\title{
Pengaruh Komitmen Organisasional, Kepuasan Kerja dan Budaya Organisasi terhadap Kinerja Karyawan pada Bento Kopi Yogyakarta
}

\author{
Rian Fajar Sidik ${ }^{1)}$ \\ Jajuk Hermawati ${ }^{2)}$ \\ Soni Kurniawan ${ }^{3)}$
}

1,2,3Prodi Manajemen, Fakultas Ekonomi, Universitas Sarjanawiyata Tamansiswa, Yogyakarta

E-mail : rianfajar290@gmail.com

\begin{tabular}{|l|l|l|}
\hline Diterima: 14 Pebruari 2021 & Direvisi: 24 Pebruari 2021 & Disetujui: 26 Pebruari 2021
\end{tabular}

\begin{abstract}
The purpose of this study was to determine the analysis of the influence of organizational commitment, job satisfaction, and organizational culture on employee performance at Bento Kopi Yogyakarta. In this study, the target population is all employees of Bento Kopi Yogyakarta, both permanent and contractual. The sample of this study is part of the target population is 100 employees of Bento Kopi Yogyakarta, where the sample is determined by the Slovin formula. The data was collected using a questionnaire or questionnaire collection method. The data analysis technique used is the regression technique which is supported by the test and classical assumptions, the data that has been obtained are processed using SPSS 21. The results of this study indicate that organizational commitment has a positive and significant effect on employee performance in accordance with the significance test carried out by the test$t$ and obtained tcount $>$ ttable $(61.695>1.66055)$ sig. amounting to $0.000 / 0.0$ so that Ho is rejected and Ha is accepted, job satisfaction has a positive and significant effect on employee performance in accordance with the significance test carried out by t-test and obtained tcount> ttable (38.241> 1.66055) sig. 0.00 / 0.00 so that Ho is rejected and $\mathrm{Ha}$ is accepted, organizational culture has a positive and significant effect on employee performance in accordance with the significance test carried out with the ttest and obtained tcount> ttable (35.798> 1.66055) sig. 0,000 so that Ho is rejected and Ha accepted.
\end{abstract}

Keywords: organizational commitment, job satisfaction, organizational culture, employee performance

\section{Pendahuluan}

Bisnis kedai kopi di Indonesia belakangan ini berkembang begitu pesat. Perubahan gaya hidup hingga perkembangan jenis musik tertentu turut mendorong jenis bisnis ini bertumbuh. Hasil riset TOFFIN perusahaan penyedia solusi bisnis berupa barang dan jasa di industri HOREKA (Hotel, restoran, dan kafe), bersama Majalah MIX MarComm mencatat 
jumlah kedai kopi di Indonesia pada Agustus 2019 mencapai lebih dari 2.950 gerai. Angka itu ternyata meningkat hampir tiga kali lipat atau bertambah sekitar 1.950 gerai dari 2016 yang hanya sekitar 1000. Angka riil jumlah kedai kopi ini bisa lebih besar karena sensus kedai kopi itu hanya mencakup gerai-gerai berjaringan di kota-kota besar, tidak termasuk kedai-kedai kopi independen yang modern maupun tradisional di berbagai daerah. Sementara itu, konsumsi kopi domestik Indonesia juga terus meningkat. Data Tahunan Konsumsi Kopi Indonesia 2019 yang dikeluarkan oleh Global Agricultural Information Network menunjukkan proyeksi konsumsi domestik (Coffee Domestic Consumption) pada 2019/2020 mencapai 294.000 ton atau meningkat sekitar 13,9\% dibandingkan konsumsi pada 2018/2019 yang mencapai 258.000 ton.

Bento Kopi merupakan satu kedai kopi yang memiliki banyak jaringan di Yogyakarta dibawah naungan Bento cafe Group, Bento Kopi didirikan oleh seseorang enterpreneur muda di Yogyakarta. Bento Kopi menyajikan berbagi varian menu dengan harga yang lumayan terjangkau. Tempat yang luas dengan interior menarik menjadi nilai tambah bagi Bento Kopi. Di Bento Kopi ini menghibur pelanggan dengan menampilakan Live musik setiap malamnya. Adapun menu dan harga makann di Bento Kopi yaitu tersedia aneka macam kopi salah satunya kopi susu, expreso kopi dan bermacam kopi lainya. Dalam segi makanan Bento Kopi juga menyediakan bermacam menu makanan seperti ayam goreng dengan kisaran harga mulai dari Rp 10.000 itu membuat Bento Kopi menjadi salah satu tempat nongkrong yang sangat disukai oleh kalangan mahasiswa selain tempatnya yang nyaman juga dengan harga produk yang sesuai dengan kantong pelanggan. Bento Kopi sendiri sudah mengembangkan sayapnya di Yogyakarta dari tahun 2012 dan bento sendiri sudah memiliki banyak cabang seperti di Sleman, Godean dan lain sebagainya, jam operasional Bento Kopi yaitu mulai buka dari jam 09.00 sampai jam 01.00 malam.

Suatu organisasi juga tidak terlepas dari komitmen organisasional. Komitmen organisasional juga memiliki keterkaitan dengan budaya organisasi. Keharmonisan tujuan yang tercapai antara karyawan dan organisasi melalui budaya akan membangun suatu komitmen organisasional dalam diri karyawan. Komitmen organisasional juga berhubungan dengan kinerja karyawan (Pratama dkk., 2020), dengan adanya komitmen maka kinerja karyawan juga akan meningkat (Adiftiya, 2014).

Kepuasan kerja juga memiliki hubungan erat dengan komitmen organisasional. Kepuasan kerja merupakan aspek pertama yang dicapai sebelum seorang karyawan memiliki komitmen organisasional dimana kepuasan kerja memiliki pengaruh yang signifikan terhadap komitmen organisasional. Dengan demikian, variabel-variabel seperti budaya organisasi, 
kepuasan kerja, dan komitmen organisasional secara teoritis memiliki hubungan yang erat dalam mempengaruhi kualitas layanan (Changgriawan, 2017). Masalah budaya merupakan salah satu hal yang esensial bagi suatu organisasi, karena akan selalu berhubungan dengan perusahaan. Budaya organisasi merupakan salah satu alat yang dapat menyatukan hubungan antara karyawan dengan organisasinya karena dengan adanya budaya tersebut akan membuat karyawan merasa bahwa dirinya termasuk bagian dari organisasi, hal tersebut juga akan berhubungan pada kinerja karyawan (Ariyanti, 2015).

Budaya organisasi dapat dilihat dari banyak hal seperti budaya kehadiran tepat waktu, disiplin karyawan dan ketepatan waktu karyawan dalam mengerjakan pekerjaannya. Semakin baik budaya yang dimiliki suatu perusahaan, akan berdampak terhadap peningkatan kinerja karyawan di perusahaan tersebut. Pernyataan tersebut didukung oleh Sagita dkk (2018) yang menunjukkan adanya pengaruh positif budaya organisasi terhadap kinerja karyawan. Kinerja karyawan bukan hanya tentang apa yang dicapai oleh seseorang karyawan, tetapi bagaimana mereka melakukannya. Arda (2017) mengatakan bahwa kinerja melibatkan sebuah prespektif yang memperhatikan pentingnya kebermaknaan dan manfaat dari upaya, hasil yang dicapai, dan cara yang digunakan. Bila Sagita dkk hanya menyebutkan unsur kinerja terdiri atas hasil dan prosesnya, maka Arda menyebutkan unsur input yang ia sebut sebagai upaya.

\section{Telaah Literatur dan Kajian Pustaka}

Komitmen organisasi merupakan dorongan dalam diri individu untuk berbuat sesuatu agar dapat menunjang keberhasilan organisasi dengan tujuan dan lebih mengutamakan kepentingan organisasi (Uddin et all 2013). Sheridan (2013) menggunakan dua pandangan tentang komitmen organisasi yaitu affective dan continuence. Hasil penelitian mengungkapkan bahwa komitmen organisasi yang bersifat affective berhubungan dengan satu pandangan profesionalisme yaitu pengabdian pada profesi. Sedangkan komitmen organisasi continuence berhubungan secara positif dengan pengalaman dan berhubungan negatif dengan pandangan profesionalisme kewajiban sosial.

Shore et al. (2012) menyatakan bahwa komitmen organisasi (organizational commitment) merupakan suatu keadaan dimana seorang karyawan memihak terhadap tujuantujuan organisasi serta memiliki keinginan untuk mempertahankan keanggotaannya dalam organisasi tersebut. Tobing (2019) mendefinisikan pengertian komitmen organisasional sebagai sebuah keadaan psikologi yang mengkarakteristikkan hubungan karyawan dengan organisasi atau implikasinya yang mempengaruhi apakah karyawan akan tetap bertahan dalam organisasi atau tidak. Sapitri dan Suryalena (2016) menyatakan bahwa komitmen 
organisasional adalah suatu ikatan psikologis. Anggota organisasi yang berkomitmen terhadap organisasinya mungkin saja mengembangkan pola pandang yang lebih positif terhadap organisasi dan dengan senang hati tanpa paksaan mengeluarkan energi ekstra demi kepentingan organisasi (Pradhan et al., 2017). Hal tersebut menunjukkan bahwa komitmen organisasional memiliki arti yang lebih dari sekedar loyalitas yang pasif, tetapi melibatkan hubungan aktif dan keinginan karyawan untuk memberikan kontribusi yang berarti pada organisasinya. Menurut Sapitri dan Suryalena (2016), karyawan yang memiliki komitmen organisasional yang tinggi adalah karyawan yang lebih stabil dan lebih produktif sehingga pada akhirnya juga akan lebih menguntungkan bagi organisasi.

Octaviana (2012), mengutip ungkapan yang diberikan oleh Locke, yang menjelaskan kepuasan kerja adalah suatu perasaan menyenangkan yang datang dari persepsi seseorang mengenai pekerjaannya atau yang lebih penting yaitu nilai tidak sehat, negatif, dan destruktif (bersifat merusak). Lebih lanjut Eustress dapat memunculkan suatu kondisi kepuasan dalam pekerjaannya. Sebagaimana diungkapkan oleh Koesmono (2015) bahwa kepuasan kerja karyawan merupakan salah satu aspek penting yang perlu diperhatikan dalam usaha peningkatan kemampuan sumber daya manusia suatu organisasi, karena dengan kepuasan kerja yang dirasakan maka seorang karyawan mampu bekerja secara optimal. Kepuasan kerja ini merupakan sikap umum individu yang bersifat individual tentang perasaan seseorang terhadap pekerjaannya. Sejalan dengan pandangan Kawiana et all (2018) mengemukakan bahwa kepuasan kerja adalah ungkapan kepuasan karyawan tentang bagaimana pekerjaan mereka dapat memberikan manfaat bagi organisasi, yang berarti bahwa apa yang diperoleh dalam bekerja sudah memenuhi apa yang dianggap penting.

Kepuasan kerja itu dianggap sebagai hasil dari pengalaman karyawan dalam hubungannya dengan nilai sendiri seperti apa yang dikehendaki dan diharapkan dari pekerjaannya. Pandangan tersebut dapat disederhanakan bahwa kepuasan kerja merupakan suatu sikap dari individu dan merupakan umpan balik terhadap pekerjaannya. Kepuasan kerja (job satisfaction) adalah cara individu merasakan pekerjaannya yang dihasilkan dari sikap individu tersebut terhadap berbagai aspek yang terkandung di dalam pekerjaan (Indrawati, 2013). Octaviana (2012) menyatakan bahwa kepuasan kerja adalah hasil dari persepsi karyawan mengenai seberapa baik pekerjaan mereka memberikan hal yang dianggap penting. Kepuasan kerja memperlihatkan perasaan karyawan tentang menyenangkan atau tidaknya pekerjaan. Kepuasan kerja (job satisfaction) adalah cara individu merasakan pekerjaannya yang dihasilkan dari sikap individu tersebut terhadap berbagai aspek yang terkandung di dalam 
pekerjaan. Kepuasan kerja adalah hasil dari persepsi karyawan mengenai seberapa baik pekerjaan mereka memberikan hal yang dianggap penting. Kepuasan kerja memperlihatkan perasaan karyawan tentang menyenangkan atau tidaknya pekerjaan (Indrawati, 2013).

Budaya organisasi sebagai sebuah sistem makna bersama yang dianut oleh para anggota yang membedakan organisasi tersebut dengan organisasi lainnya. Budaya organisasi mewakili sebuah persepsi yang sama dari para anggota organisasi. Oleh karena itu, diharapkan bahwa individu-individu yang memiliki latar belakang berbeda atau berada pada tingkatan yang tidak sama dalam organisasi dapat memahami budaya organisasi dengan pengertian yang serupa (Koesmono, 2015). Budaya merupakan berbagai interaksi dari ciri-ciri kebiasaan yang mempengaruhi kelompok-kelompok orang dalam lingkungannya. Agar budaya organisasi dapat berfungsi secara optimal, maka budaya organisasi harus diciptakan, dipertahankan, dan diperkuat serta diperkenalkan kepada karyawan melalui proses sosialisasi (Octaviana, 2012).

Kinerja adalah hasil kerja yang dapat dicapai oleh seseorang atau kelompok orang dalam organisasi. Sesuai dengan wewenang dan tanggung jawab masing - masing, dalam rangka upaya mencapai tujuan organisasi bersangkutan secara legal, tidak melanggar hukum dan sesuai dengan moral maupun etika (Sapitri dan Suryalena (2016). Menurut Tobing (2019) kinerja adalah tingkat pencapaian hasil atau pelaksanaan tugas tertentu. Kinerja perusahaan tingkat pencapaian hasil dalam rangka mewujudkan tujuan perusahaan. Manajemen kinerja adalah keseluruhan kegiatan yang dilakukan untuk meningkatkan kinerja perusahaan atau organisasi, termasuk kinerja masing-masing individu dan kelompok kerja di perusahaan tersebut. Sedangkan menurut Uddin et al. (2013) kinerja merupakan hasil kerja yang dihasilkan oleh karyawan atau prilaku nyata yang ditampilkan sesuai dengan peranannya dalam organisasi.

Kinerja merupakan suatu kondisi yang harus diketahui dan dikonfirmasikan kepada pihak tertentu untuk mengetahui tingkat pencapaian hasil suatu instansi dihubungkan dengan visi suatu organisasi atau perusahaan serta mengetahui dampak positif dan negatif dari suatu kebijakan operasional (Akbar, 2017). Secara umum, pengertian kinerja adalah hasil pekerjaan yang dicapai seseorang berdasarkan persyaratan-persyaratan pekerjaan. Suatu pekerjaan mempunyai persyaratan tertentu untuk dapat dilakukan dalam mencapai tujuan yang disebut juga sebagai standar pekerjaan. Untuk menentukan kinerja pegawai/karyawan baik atau tidak, tergantung pada hasil perbandingan dengan standar pekerjaan. Hasil pekerjaan merupakan hasil yang diperoleh seorang pegawai atau karyawan dalam mengerjakan pekerjaan sesuai persyaratan pekerjaan atau standar kinerja (Changgriawan, 2017). Menurut Sapitri dan 
Suryalena (2016), yang menyatakan bahwa kinerja adalah kesuksesan seseorang dalam melaksanakan tugas, Pada umumnya, kinerja diberi batasan sebagai kesuksesan seseorang di dalam melaksanakan suatu pekerjaan.

\section{Metode Penelitian}

Sifat yang digunakan dalam penelitian ini adalah sifat penelitian kuantitatif. Penelitian ini dilaksanakan pada Bento Kopi Yogyakarta. Populasi dalam penelitian ini adalah seluruh karyawan Bento Kopi Yogyakarta baik yang tetap maupun kontrak yang berjumlah 100 karyawan. Sampel penelitian ini adalah sebagian dari populasi sasaran adalah 100 Karyawan Bento Kopi Yogyakarta, dimana sampel di tentukan dengan rumus Slovin. Teknik pengambilan sampel yang digunakan adalah simple accidental Sampling. Teknik simple random sampling ini merupakan salah satu teknik dalam pengambilan sampel yang dilakukan secara acak sederhana. Dimana teknik ini memberikan kesempatan yang sama bagi setiap anggota populasi untuk menjadi sampel dalam penelitian.

Metode yang digunakan dalam penelitian ini adalah metode kuesioner atau angket. Penelitian ini menggunakan kuesioner untuk mengetahui apakah variabel komitmen organisasi $\left(\mathrm{X}_{1}\right)$, kepuasan kerja $\left(\mathrm{X}_{2}\right)$, budaya organisasi $\left(\mathrm{X}_{3}\right)$ berpengaruh terhadap kinerja karyawan $(\mathrm{Y})$ pada Bento Kopi Yogyakarta. Skala yang akan digunakan dalam penelitian ini adalah skala likert, yaitu suatu pertanyaan yang menunjukkan nilai tingkat kesetujuan atau tidak setuju. Dalam Penelitian ini menggunakan kuesioner tertutup yaitu angket yang disajikan dalam bentuk pernyataan-pernyataan dari setiap variabel sehingga responden hanya memberikan tanda centang pada kolom yang tersedia.

\section{Hasil Penelitian dan Pembahasan}

Pertama-tama sampel diberi beberapa pertanyaan dalam bentuk kuesioner yang terkait dengan variabel dalam penelitian, yaitu variabel komitmen organisasi $\left(\mathrm{X}_{1}\right)$, kepuasan kerja $\left(\mathrm{X}_{2}\right)$, budaya organisasi $\left(\mathrm{X}_{3}\right)$ berpengaruh terhadap kinerja karyawan $(\mathrm{Y})$. Berdasarkan hasil uji validitas dengan jumlah 100 responden dapat diketahui bahwa seluruh pernyataan mengenai komitmen organisasional, kepuasan kerja, budaya organisasi, dan kinerja karyawan yang diajukan untuk karyawan di Bento Kopi adalah valid yang dilihat dari nilai $r_{\text {hitung }}>r_{\text {tabel }}$, sehingga dapat disimpulkan bahwa seluruh pernyataan yang ada dalam kuesioner tersebut dapat dikatakan layak sebagai instrumen untuk mengukur data dalam penelitian ini. Selanjutnya dilakukan uji realibilitas untuk mengetahui apakah semua variabel dapat dinyatakan reliabel. Berdasarkan hasil penelitian diketahui bahwa nilai Cronbach's Alpha dari variabel komitmen 
organisasi sebesar 0,962 , kepuasan kerja sebesar 0,942 , budaya organisasi sebesar 0,846 , dan kinerja karyawan sebesar 0,606, sehingga dapat disimpulkan bahwa semua variabel dalam pernyataan dapat dinyatakan reliabel yang dibuktikan dengan telah terpenuhinya nilai yang disyaratkan yaitu dengan nilai Cronbach Alpha >0,60.

Berdasarkan dengan analisis deskriptif diperoleh bahwa karakterisik responden sesuai jenis kelamin karyawan sebagian besar responden termasuk dalam kategori laki-laki yaitu sebanyak 62 orang $(62,0 \%)$, sedangkan karakteristik responden berdasarkan status karyawan adalah sebagian besar responden termasuk dalam kategori dengan status karyawan belum tetap sebanyak 75 orang (75\%). Lalu karakteristik responden berdasarkan status pernikahan adalah termasuk dalam kategori belum menikah yaitu sebanyak 74 orang dengan presentase $74,0 \%$, sedangkan karakteristik responden berdasarkan umur adalah termasuk dalam kategori berumur 21-25 tahun yaitu sebanyak 49 responden dengan presentase 65,0\%, dan karakteristik responden berdasarkan pendidikan terakhir sebagian besar merupakan responden yang termasuk dalam kategori SMA sebanyak 53 orang dengan prensentase 53,0\%.

\section{Tabel 1. Uji-t Komitmen Organisasi terhadap Kinerja Karyawan}

\begin{tabular}{|c|c|c|c|c|c|c|}
\hline \multicolumn{7}{|c|}{ Coefficients $^{\mathbf{a}}$} \\
\hline \multirow{2}{*}{\multicolumn{2}{|c|}{ Model }} & Unstanc & d Coefficients & Standardized Coefficients & $\mathrm{t}$ & Sig. \\
\hline & & B & Std. Error & Beta & & \\
\hline \multirow{2}{*}{1} & (Constant) & 33,775 & ,207 & & 163,188 &, 000 \\
\hline & TKO &, 162 & ,003 & ,987 & 61,695 &, 000 \\
\hline
\end{tabular}

a. Dependent Variable: TKKN

Sumber: data hasil pengolahan peneliti, 2021

Berdasaran tabel 1 dapat disimpulkan bahwa komitmen organisasi berpengaruh positif dan signifikan terhadap kinerja karyawan dibuktikan dengan $t_{\text {hitung }}>t_{\text {tabel }}$ yaitu 61,695 > 1,66055 sehingga Ho ditolak dan Ha diterima.

Tabel 2. Uji-t Kepuasan Kerja terhadap Kinerja Karyawan

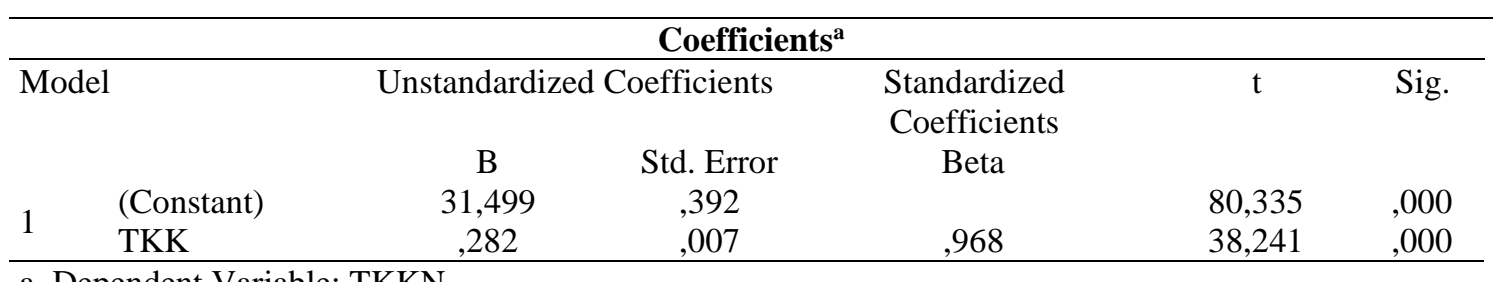

a. Dependent Variable: TKKN

Sumber: data hasil pengolahan peneliti, 2021

Berdasaran tabel 2 dapat disimpulkan bahwa kepuasan kerja berpengaruh positif dan signifikan terhadap kinerja karyawan dibuktikan dengan $t_{\text {hitung }}>t_{\text {tabel }}$ yaitu 38,241 > 1,66055 sehingga Ho ditolak dan Ha diterima.

\section{Tabel 3. Uji-t Budaya Organisasi terhadap Kinerja Karyawan}




\begin{tabular}{|c|c|c|c|c|c|c|}
\hline \multicolumn{2}{|c|}{ Model } & \multicolumn{2}{|c|}{ Unstandardized Coefficients } & $\begin{array}{c}\text { Standardized } \\
\text { Coefficients } \\
\text { Beta }\end{array}$ & $\mathrm{t}$ & Sig. \\
\hline 1 & $\begin{array}{l}\text { (Constant) } \\
\text { TBO }\end{array}$ & $\begin{array}{c}\text { B } \\
33,149 \\
, 581\end{array}$ & $\begin{array}{c}\text { Std. Error } \\
, 373 \\
, 016\end{array}$ & Beta & $\begin{array}{l}88,756 \\
35,798\end{array}$ & $\begin{array}{l}, 000 \\
, 000\end{array}$ \\
\hline
\end{tabular}

a. Dependent Variable: TKKN

Sumber: data hasil pengolahan peneliti, 2021

Berdasaran tabel 3 dapat disimpulkan bahwa budaya organisasi berpengaruh positif dan signifikan terhadap kinerja karyawan dibuktikan dengan $t_{\text {hitung }}>t_{\text {tabel }}$ yaitu 35,798 > 1,66055 sehingga Ho ditolak dan Ha diterima.

\section{Tabel 4. Komitmen Orgnisasi terhadap Kinerja Karyawan}

\begin{tabular}{lcccc}
\hline \multicolumn{4}{c}{ Model Summary $^{\mathbf{b}}$} \\
\hline Model & $\mathrm{R}$ & $\mathrm{R}$ Square & Adjusted R Square & Std. Error of the Estimate \\
1 &, $987^{\mathrm{a}}$ & 975 &, 975 &, 4264 \\
\hline a. Predictors: (Constant), TKO & & & \\
b. Dependent Variable: TKKN & & &
\end{tabular}

Sumber: data hasil pengolahan peneliti, 2021

Berdasaran tabel 4 dapat disimpulkan bahwa nilai Adjusted $R$ square sebesar 0,975. Artinya, 97,5\% komitmen organisasi dipengaruhi oleh kinerja karyawan dan sisanya 2,5\% dipengaruhi variabel lain.

\section{Tabel 5. Kepuasan Kerja terhadap Kinerja Karyawan}

\begin{tabular}{lcccc}
\hline \multicolumn{4}{c}{ Model Summary $^{\mathbf{b}}$} \\
\hline Model & $\mathrm{R}$ & R Square & Adjusted R Square & Std. Error of the Estimate \\
1 &, $968^{\text {a }}$ &, 937 &, 937 &, 6744 \\
\hline a. Predictors: (Constant), TKK & & & \\
b. Dependent Variable: TKKN & & &
\end{tabular}

Sumber: data hasil pengolahan peneliti, 2021

Berdasaran tabel 5 dapat disimpulkan bahwa nilai Adjusted $R$ square sebesar 0,937. Artinya, 93,7\% kepuasan kerja dipengaruhi oleh kinerja karyawan dan sisanya 6,3\% dipengaruhi variabel lain.

Tabel 6. Budaya Organisasi terhadap Kinerja Karyawan

\begin{tabular}{lcccc}
\hline \multicolumn{4}{c}{ Model Summary $^{\mathbf{b}}$} \\
\hline Model & $\mathrm{R}$ & $\mathrm{R}$ Square & Adjusted R Square & Std. Error of the Estimate \\
1 &, $964^{\mathrm{a}}$ &, 929 &, 928 &, 7173 \\
\hline
\end{tabular}

a. Predictors: (Constant), TBO

b. Dependent Variable: TKKN

Sumber: data hasil pengolahan peneliti, 2021

Berdasaran tabel 6 dapat disimpulkan bahwa nilai Adjusted $R$ square sebesar 0,928. Artinya, 92,8\% budaya organisasi dipengaruhi oleh kinerja karyawan dan sisanya 7,2\% dipengaruhi variabel lain.

Tabel 7. Uji F

\begin{tabular}{llllll}
\hline \multicolumn{6}{c}{ ANOVA $^{\text {a }}$} \\
\hline Model & Sum of Squares & df & Mean Square & F & Sig.
\end{tabular}




\begin{tabular}{|c|c|c|c|c|c|}
\hline & Regression & 696,934 & 3 & 232,311 & 1745,588 \\
\hline & Residual & 12,776 & 96 &, 133 & \\
\hline & Total & 709,710 & 99 & & \\
\hline
\end{tabular}

a. Dependent Variable: TKKN

b. Predictors: (Constant), TBO, TKK, TKO

Sumber: data hasil pengolahan peneliti, 2021

Berdasarkan tabel 7 diketahui $F_{\text {hitung }}=1745.588$ dan nilai signifikansi sebesar 0,000.

Berdasarkan hasil tersebut dapat disimpulkan bahwa nilai signifikansi $0.000<0.05$, artinya ada pengaruh secara bersama-sama antara komitmen organisasi, kepuasan kerja, budaya organisasi terhadap kinerja karyawan dengan nilai signifikansi di bawah 5\%. Sebagai hasil penelitian, telah dilakukan analisa data dengan menggunakan metode statistik maka dapat didiskripsikan hasil penelitian, sebagai berikut:

1. Pengaruh Komitmen Organisasi Terhadap Kinerja Karyawan

Berdasarkan hasil penelitian, dapat disimpulkan bahwa terdapat pengaruh positif dan signifikan komitmen organisasi terhadap kinerja karyawan. Sehingga H1 yang mengatakan bahwa komitmen organisasi berpengaruh positif dan signifikan terhadap kinerja karyawan diterima. Sesuai dengan hasil penelitian oleh Jajang Adiftiya (2014) komitmen organisasi berpengaruh positif terhadap kinerja karyawan pada PT. Bukit Makmur Mandiri Utama Site Kideco Jaya Agung Batu Kajang Kabupaten Paser.

2. Pengaruh Kepuasan Kerja Terhadap Kinerja Karyawan

Berdasarkan hasil analisis data diketahui bahwa kepuasan kerja terhadap kinerja karyawan berpengaruh positif dan signifikan, sehingga $\mathrm{H} 2$ yang mengatakan kepuasan kerja berpengaruh positif dan signifikan terhadap kinerja karyawan, diterima. Sesuai dengan hasil penelitian oleh Mutia Arda (2017) bahwa kepuasan kerja memiliki pengaruh positif dan signifikan terhadap kinerja karyawan.

3. Pengaruh Budaya Organisasi Terhadap Kinerja Karyawan

Berdasarkan hasil analisis data diketahui bahwa budaya organisasi terhadap kinerja karyawan berpengaruh positif dan signifikan. sehingga $\mathrm{H} 3$ yang mengatakan budaya organisasi berpengaruh positif dan signifikan terhadap kinerja karyawan diterima. Sesuai dengan hasil penelitian Alinvia Ayu Sagita, Heru Susilo, Muhammad Cahyo W.S (2018), hasil temuan berkaitan dengan budaya organisasi adalah adanya pengaruh yang positif dan signifikan terhadap kinerja karyawan pada PT Astra Internasional

4. Hubungan Komitmen Organisasi, Kepuasan Kerja dan Budaya Organisasi terhadap Kinerja Karyawan 
Berdasarkan pengujian secara simultan diketahui komitmen organisasi, kepuasan kerja dan budaya organisasi berpengaruh positif dan signifikan terhadap kinerja karyawan. sehingga H4 yang mengatakan komitmen organisasi, kepuasan kerja dan budaya organisasi secara bersamaan berpengaruh positif dan signifikan terhadap kinerja karyawan, diterima. Hasil ini sesuai dengan penelitian Anisa Noviani Rachmah (2017) menyatakan bahwa komitmen oganisasional, kepuasan kerja, dan budaya organisasi tperpengaruh signifikan positif terhadap kinerja karyawan Hotel Pekanbaru.

\section{Simpulan}

Berdasarkan hasil penelitian yang telah dilakukan mengenai komitmen organisasional, kepuasan kerja, dan budaya organisasi terhadap kinerja karyawan dapat disimpulkan bahwa komitmen organisasi berpengaruh positif dan signifikan terhadap kinerja karyawan yang diperoleh nilai thitung $>t_{\text {tabel }}$ yaitu 61,695 > 1,66055 dan sig. sebesar 0,000/0,0 hipotesis 1 yang menyatakan komitmen organisasi berpengaruh positif dan signifikan terhadap kinerja karyawan diterima. Kepuasan kerja terhadap kinerja karyawan berpengaruh positif dan signifikan yang diperoleh nilai $t_{\text {hitung }}>\mathrm{t}_{\text {tabel }}$ yaitu 38,241 > 1,66055 dan sig. 0,00/0,00 hipotesis 2 yang menyatakan kepuasan kerja berpengaruh positif dan signifikan terhadap kinerja karyawan diterima. Budaya organisasi terhadap kinerja karyawan berpengaruh positif dan signifikan yang diperoleh nilai $t_{\text {hitung }}>\mathrm{t}_{\text {tabel }}$ yaitu 35,798 > 1,66055 dan sig. 0,000 $(0,000<0,05)$ hipotesis 3 yang menyatakan budaya organisasi berpengaruh positif dan signifikan terhadap kinerja karyawan diterima. Pengujian secara simultan variabel komitmen organisasi, kepuasan kerja dan budaya organisasi terhadap kinerja karyawan berpengaruh positif dan signifikan karena mendapatkan hasil $\mathrm{t}_{\text {hitung }}>\mathrm{t}_{\text {tabel }}$ tabel dan nilai sig $<$ dari 0,05 atau 5\% maka dapat disimpulkan bahwa variabel komitmen organisasi, kepuasan kerja dan budaya organisasi terhadap kinerja karyawan berpengaruh positif dan signifikan dan hipotesis 4 diterima.

\section{Daftar Referensi}

Adiftiya, J. (2014). Pengaruh Komitmen Organisasi Terhadap Kinerja Karyawan Pada PT. Bukit Makmur Mandiri Utama Sitekideco Jaya Agung Batu Kajang Kabupaten Paser. Jurnal Ilmu Administrasi Bisnis, 2(4), 8-11.

Akbar, A., Al Musadieq, M., \& Mukzam, M. D. (2017). Pengaruh Komitmen Organisasional Terhadap Kinerja (Studi pada Karyawan PT PELINDO Surabaya. Jurnal Administrasi Bisnis, 47(2), 33-38.

Arda, M. (2017). Pengaruh Kepuasan Kerja Dan Disiplin Kerja Terhadap Kinerja Karyawan Pada Bank Rakyat Indonesia Cabang Putri Hijau Medan. Jurnal Ilmiah Manajemen dan Bisnis, 18(1), 45-60.

Arianty, N. (2015). Pengaruh budaya organisasi terhadap kinerja pegawai. Jurnal Ilmiah Manajemen dan Bisnis, 14(2) 6-9. 
Changgriawan, G. S. (2017). Pengaruh kepuasan kerja dan motivasi kerja terhadap kinerja karyawan di One Way Production. Agora, 5(2) 5-7.

Indrawati, A. D. (2013). Pengaruh kepuasan kerja terhadap kinerja karyawan dan kepuasan pelanggan pada rumah sakit swasta di kota denpasar. Jurnal Manajemen, Strategi Bisnis, dan Kewirausahaan, 7(2), 135-142.

Kawiana, I. G. P., Dewi, L. K. C., Martini, L. K. B., \& Suardana, I. B. R. (2018). The influence of organizational culture, employee satisfaction, personality, and organizational commitment towards employee performance. International Research Journal of Management, IT And Social Sciences, 5(3), 35-45.

Koesmono, H. T. (2015). Pengaruh budaya organisasi terhadap motivasi dan kepuasan kerja serta kinerja karyawan pada sub sektor industri pengolahan kayu skala menengah di Jawa Timur. Jurnal Manajemen Dan Kewirausahaan, 7(2), 171-188.

Octaviana, n. (2012). Pengaruh budaya organisasi terhadap motivasi dan kepuasan kerja serta kinerja karyawan pada pt. mirota kampus di yogyakarta. (Doctoral Dissertation, UPN" Veteran" Yogyakarta). 8(3), 11-15.

Pradhan, R. K., \& Jena, L. K. (2017). Employee performance at workplace: Conceptual model and empirical validation. Business Perspectives and Research, 5(1), 69-85.

Pratama, IGAAEB, Surtha, IW., Mahayasa, IGA. (2020). Pengaruh Gaya Kepemimpinan Transformasional Terhadap Kinerja Karyawan Dengan Komitmen Organisasi Sebagai Variabel Intervening Pada Graha Kaori Group Di Gianyar. JUIMA: Jurnal Ilmu Manajemen. 10 (1), 46-53.

Sagita, A. A., Susilo, H., \& Cahyo WS, M. (2018). Pengaruh Budaya Organisasi Terhadap Kinerja Karyawan Dengan Motivasi Kerja Sebagai Variabel Mediator (Studi Pada PT Astra Internasional, TBK-Toyota (Auto2000) Cabang Sutoyo Malang. Jurnal Administrasi Bisnis, 57(1), 73-82.

Sapitri, R., \& Suryalena, S. (2016). Pengaruh komitmen organisasi terhadap kinerja karyawan Perusahaan Listrik Negara area Pekanbaru. (Doctoral dissertation, Riau University). 2(4), 9-12.

Sheridan, J. E. (2012). Organizational Culture And Employee Retention. Academy Of Management Journal, 35(5), 1036-1056.

Shore, Lynn McFarlane dan Harry J.Martin. (2019.) Job Satisfaction and Organizational Commitment in Relation to Work Performance and Turnover Intentions, Human Relations, 42(7): 625-638.

Tobing, D. S. K. (2019). Pengaruh komitmen organisasional dan kepuasan kerja terhadap kinerja karyawan PT. Perkebunan Nusantara III di Sumatera Utara. Jurnal Manajemen dan Kewirausahaan, 11(1), 31-37.

Uddin, M. J., Luva, R. H., \& Hossian, S. M. M. (2013). Impact of organizational culture on employee performance and productivity: A case study of telecommunication sector in Bangladesh. International Journal of Business and Management, 8(2), 63. 